Bundesgesundheitsbl 2012 $\cdot 55: 1044-1056$ DOI 10.1007/s00103-012-1520-5

(c) Springer-Verlag 2012
Mitteilungen des Arbeitskreises Blut des Bundesministeriums für Gesundheit

\section{Arbonematoden - durch Arthropoden übertragbare Nematoden-Infektionen}

\author{
Stellungnahmen des Arbeitskreises Blut \\ des Bundesministeriums für Gesundheit
}

Der Arbeitskreis Blut des Bundesministeriums für Gesundheit gibt als nationales Beratungsgremium Stellungnahmen zu neuartigen Erregern ab, bewertet neue Erkenntnisse zu bekannten Erregern und erarbeitet entsprechende Empfehlungen für die Fachöffentlichkeit. Diese Serie von Stellungnahmen zu einzelnen Erregern werden als Zusammenfassung des aktuellen Wissensstandes veröffentlicht, speziell unter transfusionsmedizinisch relevanten Aspekten (Bundesgesundhbl., 41, 53, 1998).

Frühere Beiträge befassten sich mit der Creutzfeldt-Jakob-Erkrankung, dem Parvovirus $B 19$ und dem GB-Virus Typ $C$ (Hepatitis-G-Virus) (Bundesgesundheitsbl., 41, 78-90, 1998), HTLV-1/2 (Bundesgesundheitsbl., 41, 512-517, 1998), Yersinia enterocolitica (Bundesgesundheitsbl., 42, 613, 1999), TT-Virus (Bundesgesundheitsbl., 43, 154-156, 2000), Hepatitis-BVirus (HBV) (Bundesgesundheitsbl., 43, 240-248, 2000), Humanes Cytomegalovirus (HCMV) (Bundesgesundheitsbl., 43, 653-659, 2000), Hepatitis-A-Virus (Bundesgesundheitsbl., 44, 844-850, 2001), Treponema pallidum (Bundesgesundheitsbl. 45, 818-826, 2002), Hepatitis-CVirus (Bundesgesundheitsbl. 46, 712722, 2003), Humanes Immunschwächevirus (HIV) (Bundesgesundheitsbl. 47, 83-95, 2004), Arboviren - durch Arthropoden übertragbare Viren (Bundesgesundheitsbl. 47, 910-918, 2004), Coxiella burnetii - Erreger des Q-(query) Fiebers (Bundesgesundheitsbl. 48, 814-821, 2005), Va- riante Creutzfeldt-Jakob-Krankheit (Bundesgesundheitsbl. 48, 1082-1090, 2005), Influenzaviren (Bundesgesundheitsbl. 50, 1184-1191, 2007), Arbobakterien (über Arthropoden übertragbare Bakterien) (Bundesgesundheitsbl. 50, 1192-1207, 2007), Hepatitis-E-Virus (Bundesgesundheitsbl. 51, 90-97, 2008), Malaria (Bundesgesundheitsbl. 51, 236-249, 2008), Arboprotozoen (Bundesgesundheitsbl. 52, 123 146, 2009), Orthopockenviren: Infektionen des Menschen (Bundesgesundheitsbl. 53, 957-972, 2010), Humanes Cytomegalievirus (HCMV) (Bundesgesundheitsbl. 53, 973-983, 2010), Parvovirus B19 (Bundesgesundheitsbl. 53, 944-956, 2010), Dengue Fieber Virus (DENV) (Bundesgesundheitsbl. 54, 892-903, 2011), XMRV (Bundesgesundheitsbl. 55, 1057-1060) und West-Nil-Virus (Bundesgesundheitsbl. 55, 1024-1043)

\section{Arbonematoden - durch Arthropoden übertragbare Nematoden-Infektionen}

Einige Alphaviren und Flaviviren, wie die transfusionsrelevanten Chikungunyaund das West-Nil-Virus, werden durch Mücken übertragen und als Arboviren bezeichnet. Unter den Bakterien werden Coxiella burnetii [1], Borrelia, Ehrlichia und Anaplasma typischerweise über Zecken übertragen, sie sind sog. Arbobakterien [2]. Von den Protozoen werden Plasmodien über Mücken, Leishmanien über Sandfliegen (Phlebotomus), und bei- spielsweise Trypanosomen über Raubwanzen (Triatoma) übertragen, und unter den Arboprotozoen zusammengefasst [3]. Folgende Nematoden werden durch Arthropoden auf den Menschen übertragen: Mikrofilarien von Wuchereria bancrofti über Mücken (Culex), Onchocera [Oncocerca volvulus - Knäuelfilarie in Afri$\mathrm{ka}$, Onchocerca caecutiens - Blendfilarie in Südamerika] über die Kriebelmücken (Simulium, black fly) und Loa loa (Wanderfilarie, African eye worm) über Bremsen (Tabaniden) - sie werden hier unter den Arbonematoden zusammengefasst.

\section{Wissensstand über die Erreger}

Helminthen (Würmer) werden unterteilt in Nematoden (Rundwürmer), Trematoden (Saugwürmer) und Cestoden (Bandwürmer). Unter den Nematoden werden unterschieden die intestinalen Rundwürmer und die Gewebsrundwürmer. Die intestinalen Nematoden werden unterteilt in die Fadenwürmer Ankylostoma duodenale, Ascaris lumbricoides und Strongyloides stercoralis, die während der Reifung der Larve eine Lungenpassage vollziehen, um wieder ins Intestinum zu gelangen; sie haben nur eine kurze haematogene Phase. Bei den Trematoden reifen die Larven von den im Pfortaderkreislauf lebenden und dort verleibenden Schistosoma (S. mansoni, S. haematobium und S. japonicum) ebenfalls über eine Lungenpassage und somit können Larven auch kurzfristig im Blut vorhanden sein. 
Die Würmer wandern nachts in den Venen zu Blase und Rektum und legen dort nach Durchbohren der Gefäßwand die Eier im Gewebe ab. Die Eier werden mit Urin und Faeces ausgeschieden. Die sich aus den Eiern entwickelnden Larven werden mit Wasser oder Nahrung oder über Hautpassage aufgenommen und fallen nicht unter die Definition Arbonematoden. Sie sind nicht transfusionsrelevant und werden deswegen in diesem Artikel nicht abgehandelt [4].

$\mathrm{Zu}$ den Gewebsrundwürmern gehören Trichinella spiralis, Dracunculus medinensis und Toxocara canis, die gewebsständig bleiben und weder Eier noch Mikrofilarien in die Blutbahn abgeben; sie werden nicht über Arthropoden übertragen. Nematoden, die über Arthropoden auf den Menschen übertragen werden, sind die lymphatischen Filarien Wuchereria bancrofti, Brugia malayi und Brugia timori, und die im Gewebe lebenden Mansonella, Onchocerca und Loa loa.

\subsection{Erregereigenschaften}

\section{Lebenszyklus}

Arbonematoden sind zweigeschlechtliche Würmer mit einem Vermehrungszyklus im Menschen oder Primaten und einem Reifungszyklus der Larve in den entsprechenden Arthropoden (• Abb. 1). Nach Stich einer weiblichen Mücke oder Bremse, die Blut für das Reifen ihrer Eier benötigt, verlassen die L3-Larven die Speicheldrüse des Arthropoden und schlüpfen von der Hautoberfläche durch den Stichkanal ins Unterhautgewebe [5]. Von dort gelangen sie in die Lymphgefäße, entwickeln sich zur L4-Larve und folgend nach weiteren 6-9 Monaten zu sexuell reifen weiblichen und männlichen Würmern. Die Würmer verbleiben in den afferenten Lymphgefäßen der Extremitäten und des männlichen Genitals und in der Haut (- Abb. 1). Vom befruchteten weiblichen Wurm werden täglich etwa 10-20.000 Eier, aus denen die L1-Larven schlüpfen, sog. Mikrofilarien, in die Lymph- und Blutbahn abgegeben.

Wenn ein infizierter Mensch von Mücke oder Bremse gestochen wird, werden L1-Larven mit der Blutmahlzeit aufgenommen, bohren sich im Arthropoden durch dessen Darmwand und entwickeln sich nach etwa 2 Wochen in den Thoraxmuskeln zu L2- und L3-Larven [6]. Die L3-Larve wandert in den Kopf des Arthropoden, dann in die Region der Kauwerkzeuge und wird beim Stich auf der menschlichen Haut deponiert. Eine Vermehrung der Larven im Arthropoden findet nicht statt, die Absterberate der L3Larve ist sehr gering [5].

\section{Lymphatische Filarien}

Wuchereria bancrofti. Der adulte Wurm mit einer Größe von etwa 4-8 cm (weiblich > männlich) verbleibt in den lymphatischen Gefäßen, die über Entzündungsvorgänge und mechanisch teilweise obliterieren und dilatieren. Der Wurm kann 5-8 Jahre leben und gibt während der Zeit Millionen von Mikrofilarien (L1-Stadium), ca. 10.000 täglich mit einer Größe von 100-150 $\mu \mathrm{m}$, ins lymphatische System und ins Blut ab [5]. Die größte Ausschüttung von Mikrofilarien findet sich nachts während der Mückenstechzeit, von etwa 22:00 bis 4:00 [6; 7]. Die Mikrofilarien werden von der Mücke aufgenommen, reifen in dieser zum L3-Stadium heran und können beim Blutsaugakt wieder übertragen werden. Viele Mückenarten wie Anopheles, Culex, Aedes, Mansonia, Culicoides und andere übertragen Mikrofilarien. Culex-Spezies verbreiten $\mathrm{Wu}$ chereria bancrofti vorzugsweise in urbanen und semi-urbanen Regionen, Anopheles in ländlichen Regionen, besonders in Afrika, und Aedes ist an der Übertragung von Brugia malayi beteiligt [8].

Der Wurm ist von der Bakterienspezies Wolbachia besiedelt. Wolbachia sind für die Larvenentwicklung und Geschlechtsdetermination essentiell. Wenn Wolbachia fehlen, z. B. durch Behandlung mit Tetrazyklin, ändert sich das Geschlechterverhältnis der Larven mit einer Präferenz von männlichen Larven, da weibliche Larven eine dichtere Besiedlung mit Wolbachia für die Differenzierung benötigen [9]. Der adulte Wurm von Wuchereria bancrofti kann nur etwa 12 Monate ohne Wolbachiabesiedelung überleben [7].

Brugia malayi und Brugia timori. Der adulte Wurm ist morphologisch dem von Wuchereria bancrofti sehr ähnlich. Die
Mikrofilarie von B. timori ist jedoch deutlich grösser, die Kopfscheide (sheath) lässt sich in der Giemsa-Färbung nicht anfärben und die beiden Kerne finden sich im hinteren Ende, während die von W. bancrofti und B malayi im Schwanz der Larve liegen [6]. Der Endosymbiont Wolbachia ist für die Entwicklung der Larven und Überleben des Wurmes ebenfalls essentiell.

Loa loa (Wanderfilarie, afrikanischer Augenwurm). Die Übertragung erfolgt durch tagaktive Bremsen der Spezies Chrysops. Der adulte Wurm misst 3-7 $\mathrm{cm}$ und entwickelt sich innerhalb von etwa 6-12 Monaten aus der Larve. Der Wurm lebt in der Haut, kommt gelegentlich auch im Auge vor. Eier werden vom reifen weiblichen Wurm tagsüber ins Blut freigesetzt und entwickeln sich zur L1-Larve. Die weitere Entwicklung L2 zu L3 vollzieht sich in der Bremse innerhalb von etwa 2 Wochen nach Aufnahme der Mikrofilarien während der Blutmahlzeit (• Abb. 1). Mikrofilarien tragen eine Kopfscheide, die bei der Reifung in der Bremse abgeschert wird. Der adulte Wurm lebt im Menschen 4-12 Jahre, Mikrofilarien überleben 6-12 Monate [10].

Der Endosymbiont Wolbachia fehlt bei Loa loa und ist für die Wurmentwicklung nicht notwendig. Wesentliche nichtmenschliche Wirte von Loa loa sind Drill und Mandrill (Mandrillus leucophaeus, Mandrillus sphinx), ferner sind in Westund Zentralafrika Weißnasenaffen (Cercopithecus nictitans) und Mona-Affen (Cercopithecus mona) durchseucht.

Mansonella. Mansonella perstans wird durch Culicoides übertragen. Der adulte Wurm, weiblich ca. 7-8 cm, männlich ca. 4-5 cm lang, bevorzugt seröse Höhlen des Körpers und gibt Eier, bzw. die mit Kopfscheide bewehrten Mikrofilarien ab. M. perstans kommt in Zentral- und Nordafrika, Südamerika und der Karibik vor.

Mansonella ozzardi wird durch $\mathrm{Cu}$ licoides und Simulium amazonicum in Süd- und Zentralamerika und der Karibik übertragen. Die Mikrofilarien tragen keine Kopfscheide.

Mansonella streptocerca wird durch Culicoides übertragen. Der Wurm ist endemisch im Regenwald von Ost- und Zen- 


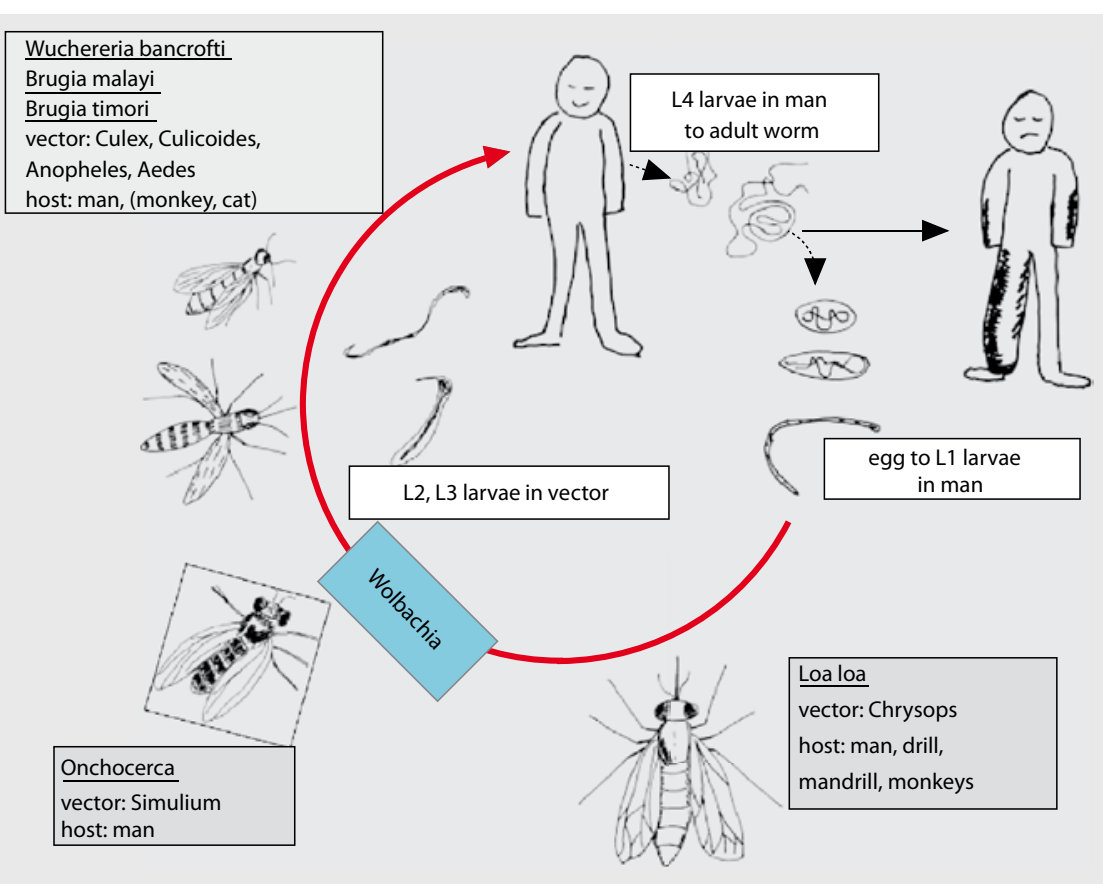

Abb. 1 S Schema des Replikationszyklus von Arbonematoden im Vektor (Bremse, Kriebelmücke, Anopheles und Culicoides) und Wirt, hier Mensch. Adulte weibliche Würmer produzieren $>10.000$ Eier pro Tag, aus denen sich zügig die Mikrofilarien bis zur L1-Larve entwickeln (gepunkteter Pfeil). Im Vektor findet die weitere Reifung zur L3-Larve statt (roter Pfeil mit durchgezogener Linie) - nur bei Loa loa ohne Einflussnahme von Wolbachia Bakterien. Beim Stich überträgt der Vektor L3-Larven auf den Menschen, die zur L4-Larve reifen und sich dann zum adulten kleineren männlichen und größeren weiblichen Wurm entwickeln (Quelle: Prof. Dr. L. Gürtler).
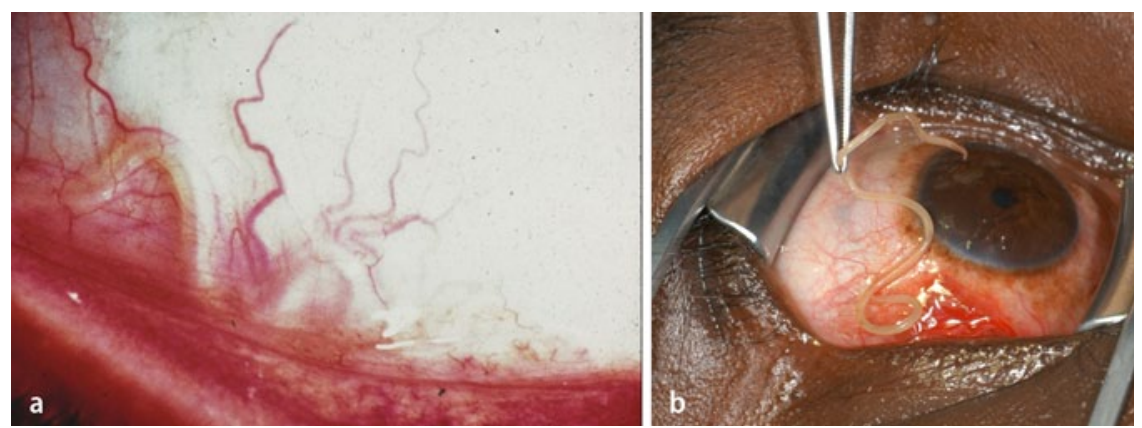

Abb. 2 A Loa loa-Infektion des Auges. A. gewundene Mikrofilarie in der Konjuktivaltasche und B. nach Extraktion gehalten zwischen den Branchen einer Pinzelle. Foto: Prof. Volker Klauß, Augenklinik der Universität München

tralafrika. Die Mirkofilarien leben vorzugsweise in der Haut und können durch Hautbiopsie (Hautstanze, skin snip) anhand ihres angelhakenförmigen Schwanzes identifiziert werden.

\section{Onchocerca (Knäuelfilarie, Blentfila-}

rie). Der Wurm und die Mikrofilarien leben im Wesentlichen in der Unterhaut. Tausende von Mikrofilarien ohne Kopfscheide werden täglich vom adulten weiblichen Wurm (Größe etwa 40 x 0,03 cm) freigesetzt. Der männliche Wurm ist klei- ner (etwa $3 \times 0,03 \mathrm{~cm}$ ) und überlebt wie der weibliche in Hautknoten, die einfach palpierbar sind [5; 7]. Mikrofilarien überleben im Menschen 12-18 Monate, wenn sie absterben, entwickelt sich eine juckende chronische Entzündung durch die Freisetzung von Wolbachia. Mikrofilarien haben eine Länge von etwa $200 \mu \mathrm{m}$; sie können bei Befall des Auges direkt oder mit der Spaltlampe gesehen werden.

Wolbachia unterhält und beschleunigt die Entzündungsvorgänge über Chemokin-Produktion, die zu einer Infiltration von neutrophilen Granulozyten am $\mathrm{Ab}$ sterbeort der Mikrofilarien führen. Ferner wird über die Endosymbiose mit Wolbachia eine Immunsuppression und eine $\mathrm{T}$ Helfer-Lymphozyten bedingte Th2-Antwort hervorgerufen. Onchocerca aus Savannenregionen, wo die Flussblindheit (Onchocercose) weit verbreitet ist, sind mit wesentlich mehr Wolbachia besiedelt als die in anderen Regionen, sodass der Einfluss der Bakterien für die Manifestation der Blindheit ein essentieller Faktor zu sein scheint.

Dirofilaria repens ist ein Parasit von Hunden und Katzen. Die Filarien entwickeln sich inkomplett im Auge des Menschen [5], sie verbleiben in den meisten Fällen in der Haut. Dirofilaria kommt auch in Südeuropa vor, einige Fälle mit lokaler Häufung wurden in Serbien beschrieben [11]. Der Mensch ist Fehlwirt, deswegen wird Dirofilaria nicht weiter abgehandelt.

Setaria labiatopapillosa, S. digitata. Diese Mikrofilarien kommen in Haustieren in Ostasien und Südeuropa vor und werden gelegentlich auf den Menschen übertragen, in dem sie subkonjunktivale Entzündungen verursachen. Encephalomyelitis, ausgelöst durch Setaria ist beschrieben [12]. Transfusionsmedizinische Bedeutung hat Setaria nicht.

\section{Vektoren}

Mücken. In ländlichen Regionen überträgt besonders Anopheles Mikrofilarien. Spezies sind An. gambiae, An. funestus, An. punctulatus und weitere 40 Spezies; in städtischen Regionen Culex quinquefasciatus, $\mathrm{Cu}$. pipiens u.a.; ferner Aedes wie Ae. polynesiensis und Mansonia und Ochlerotatus [8; 13].

Bremsen. Unter den Bremsen (Tabanidae) überträgt die Parasiten vor allem diejenigen des Genus Chrysops, besonders Ch. silacea und Ch. dimidiata, die tagaktiv und anthropophil sind, ferner Ch. distinctipennis, Ch. zahrai, Ch. centurionis und Ch. longicornis abhängig von der Region [10].

Kriebelmücke. Die Entwicklung der Simulium-Larven ist an sauerstoffreiches 
Wasser gebunden; folglich ist die Kriebelmücke dort zu finden, wo kleine Wasserfälle oder Stromschnellen vorhanden sind. Das sind die Galeriewälder der Savannen, besonders in Westafrika und Regenwaldregionen in Zentral- und Ostafrika, ferner Zentral- und Südamerika [14]. Kriebelmücke und Onchocerca sind an den Menschen adaptiert.

\subsection{Infektion und Infektionskrankheit}

\section{Pathogenese}

\section{Wuchereria bancrofti, Brugia malayi und Brugia timori. Typische Sympto-} me im Menschen entwickeln sich erst $\mathrm{ab}$ einem Lebensalter von 10 Jahren und dann nur in einer Minderheit der Infizierten, sodass wahrscheinlich neben immunologischen genetische Faktoren bei der Krankheitsausprägung beteiligt sind [15; 16 ; ]. Die Infektion verläuft immer chronisch. Co-Infektionen wie Malaria und Tuberkulose verstärken die immunsuppressiven Aktionen, die durch die Filarien hervorgerufen werden [17]. Durch die Filarien-Infektion wird die Th1- und Th17-Lymphozyten-Reaktion gegen Mycobacterium tuberculosis eingeschränkt [17]. Zusätzlich wird ein Teil der Pathogenese durch freigesetzte Wolbachia des absterbenden Wurms ausgelöst. Komponenten von Wolbachia führen zur Aktivierung von Makrophagen, von Complement und zur Anlockung von neutrophilen Granulozyten. Der Wurm wird durch ein inflammatorisches Granulom abgekapselt, Th1- und Th17-Helfer-Lymphozyten werden durch Wolbachia-Komponenten aktiviert [7]. Nematoden-Komponenten führen zu einer Th2-Antwort mit allergischer Reaktion, wie Eosinophilie und IgE-Produktion.

Nach Jahren der Infektion führt eine Schädigung der Lymphgefäße zu Hydrocele und Lymphoedem mit Elephantiasis. Die Symptome, besonders auf der Haut, werden durch opportunistische Infektionserreger verstärkt. Erhöhte Spiegel von VEGF-A (vascular endothelial growth factor) sind mit der Ausbildung der Hydrocele und VEGF-C mit dem Lymphoedem assoziiert. Homozygotie von $\mathrm{C} / \mathrm{C}$ in Position 260 von VEGF-A und Häufigkeit der Hydrocele sind in Ghana assoziiert [15]. Die Behandlung mit Tetracyclin senkt die VEGF-A Spiegel $a b$ und ist ein Hinweis, dass die VEGF-A Produktion durch Wolbachia ausgelöst wird. In Patienten mit einer chronischen Mikrofilarien-Infektion ist die Blutgerinnung vermindert [18].

Loa loa. Nach Übertragung von Loa loa durch Bremsenstich treten die ersten Symptome nach etwa 5 Monaten auf, eine klinische Latenz kann aber bis zu 13 Jahren bestehen. Bei geringer Wurmbesiedelung und bei Kindern treten häufig keine Symptome auf. Beim Augenbefall benötigt ein Wurm etwa 30-60 min, u. U. einen Tag, um ins Auge einzudringen ( $\bullet$ Abb. 2a,b). Die Wanderung ist begleitet von Photophobie, Jucken, Schmerzen und Schwellung. Überwärmung des Auges kann die Wanderung induzieren. Die lytischen Vorgänge im Auge können zu Blindheit führen. Calabar-Schwellung (oder Beule), ein kurzzeitiges schmerzloses, teils juckendes Oedem meist der Unterarme, ist die Ausbildung einer subkutanen allergischen Reaktion gegen Loa loa, welches besonders bei Zuwanderern in endemische Regionen auftritt. Begleitet ist die Calabar-Schwellung von einer Eosionphilie [10].

Onchocerca. Nach Übertragung laufen pathogenetische Schädigungen im Wesentlichen in der Haut ab. Vom WurmKonvolut (• Abb.3a), meist aus mehreren männlichen und weiblichen Würmern bestehend, werden täglich Tausende von Mikrofilarien abgegeben (• Abb. 3b), die eine lokale Entzündung auslösen, die sich mit anhaltendem Juckreiz, akuter und chronischer papulärer Dermatitis und lichenoider sog. Oncho-Dermatitis (Sklerodermie, Erysipel) äußert. Die Haut kann depigmentieren, sog. LeopardenHaut, die Elastizität der Haut ist eingeschränkt - diese Veränderungen werden durch eine Hyper-Immunreaktion (Th2Antwort) ausgelöst [19; 7]. Die afrikanische Onchocercose (O. volvulus) manifestiert sich typischerweise am Rumpf, die amerikanische (O. caecutiens) am Kopf.

Onchocerca-Mikrofilarien haben eine hohe Affinität für das Auge. Nach Einwanderung sterben sie dort ab, lösen eine schwere Entzündungsreaktion aus mit Keratitis und Irodocyclitis, schließlich Retinitis und Schädigung des Nervus opticus, die zu Einschränkung des Sehvermögens und schließlich zu Blindheit führt $\rightarrow$ Flussblindheit. Die okuläre Entzündungsreaktion wird durch Wolbachia-Komponenten gesteigert, die Einwanderung von neutrophilen Granulozyten führt zur Eintrübung der Cornea [7].

Der tägliche Umsatz, Zahl der abgestorbenen und neu produzierten Mikrofilarien, beträgt 10.000 bis 300.000 Mikrofilarien; im Körper können bis zu 150 Millionen Mikrofilarien vorhanden sein [20].

\subsection{Epidemiologie}

Da Mikrofilarien über Vektoren übertragen werden, ist die Verbreitung eng an die Habitate des Vektors gebunden. Weltweit sind von Wuchereria bancrofti ca. 110 Millionen Menschen betroffen, von Brugia etwa 10 Millionen, von Onchocerca etwa 37 Millionen, von Loa loa und Mansonella je unter 10 Millionen. Endemische Regionen (• Abb.4) sind für:

Wuchereria bancrofti. Afrika südlich der Sahara, Süd-Ost Asien, Ozeanien, Karibik und begrenzte Regionen in Südamerika. Länder mit hyperendemischer Prävalenz sind Indien, Indonesien, Neu-Guinea, Nigeria, Ghana, Kenia und Tansania. Vektoren sind die dämmerungsaktiven Anopheles, und die nachtaktiven $\mathrm{Cu}$ lex und Aedes Mücken. Bisher ist kein tierisches Reservoir bekannt.

Brugia malayi. Süd- und Südostasien und pazifische Region. Neben dem Menschen sind Katzen und Primaten ein Reservoir. Vektor wie Wuchereria bancrofti.

Brugia timori. Neu-Guinea und Inseln von Ostindonesien. Vektor wie Wuchereria bancrofti.

Loa loa. West- und Zentralafrika bis nach Uganda und Äthiopien. Reservoir sind Primaten, besonders Drill (Mandrillus leucophaeus) und Mandrill (Mandrillus sphinx) [10]. Ein Fall einer Loa loa-Infektion des Augenlides bei einem afrikanischen Studenten wurde in Deutschland berichtet [21]. Vektoren sind die tagakti- 

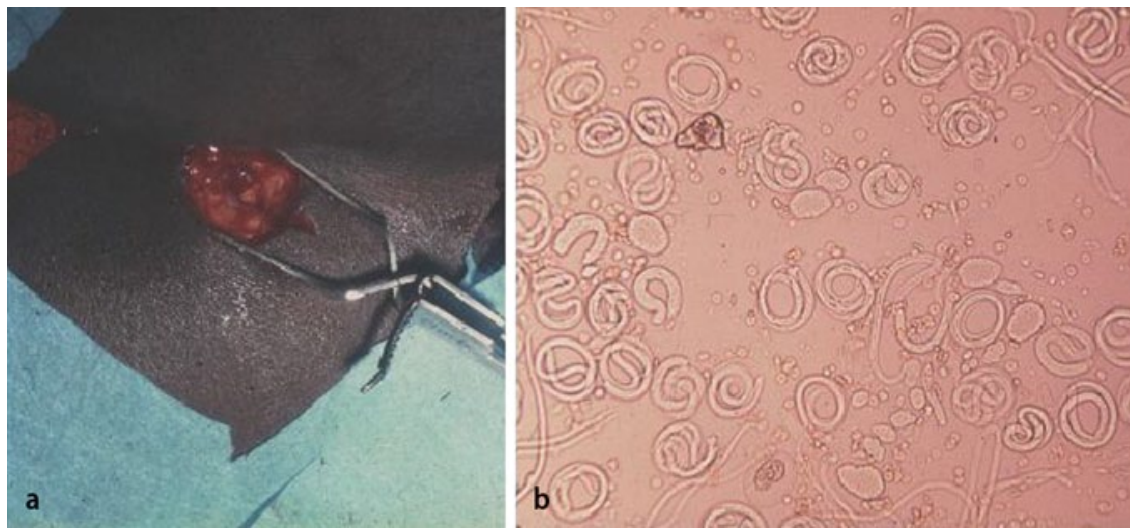

Abb. $3 \Delta$ Onchocherca volvulus. A: Konvolut und Präparation der darin enthaltenen Würmer, die von Bindegewebe umgeben sind. B: aus einer Hautbiopsie (skin snip) ausgewanderte Mikrofilarien im mikroskopischen Nativpräparat. Die Mikrofilarien-Länge entspricht etwa 250 bis $300 \mu \mathrm{m}$. Foto: Prof. Thomas Löscher, Abteilung für Tropenmedizin, Universität München

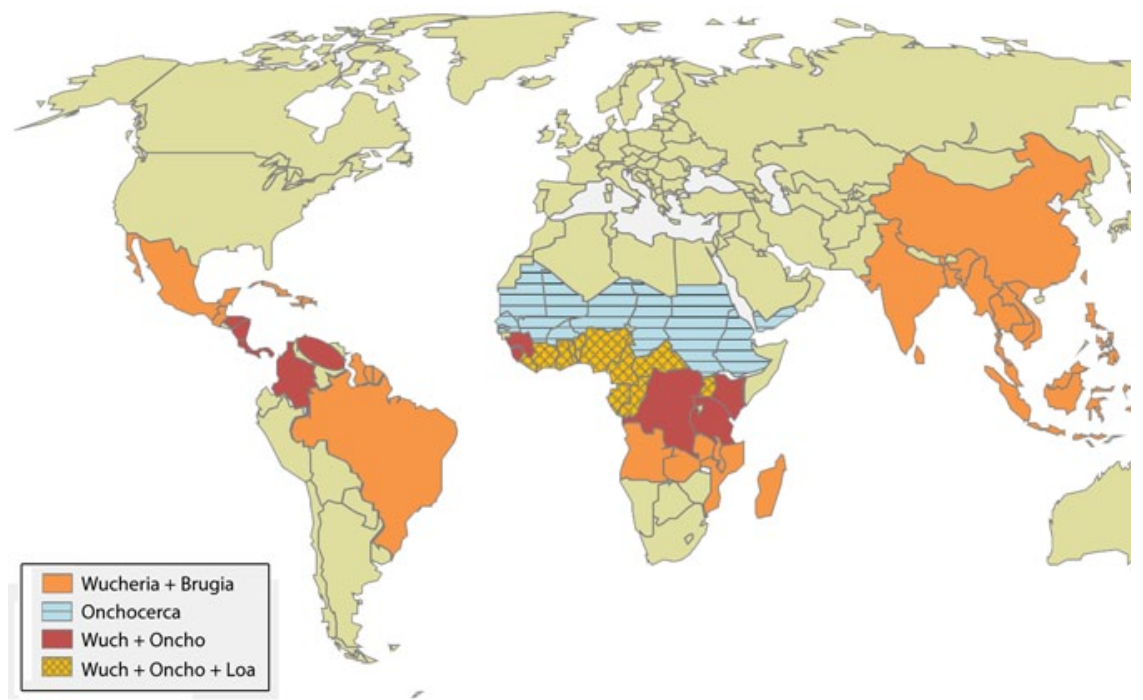

Abb. $4 \Delta$ Grobe Darstellung der weltweiten Verbreitung von Arbonematoden nach Ländern. Die endemischen Regionen von Wuchereria bancrofti und Brugia sind in oker, von Onchocerca in hellblau mit horizontalen Linien und überlappende Regionen in purpur markiert. Zusätzliche Loa loa-Infektionen beschränken sich auf einen Gürtel in West- und Zentralafrika, sie sind gelb und schräg schraffiert (Quelle: Prof. Dr. L. Gürtler).

ven Chrysops silacea und Ch. dimidiata und weitere Chrysops-Arten.

Mansonella. M. perstans - Afrika südlich der Sahara, Nordafrika, nördliche Küste von Südamerika; M. ozzardi - Karibik, Zentral- und Südamerika; M. streptocerca - West- und Zentralafrika. Vektor für M. ozzardi sind Culicoides und Simulium amazonicum, für M. perstans und M. streptocerca Culicoides.

Onchocerca. Afrika südlich der Sahara, besonders die Savannenregionen von Nigeria bis zum Kongo und deren Gale-
Die derzeitige Epidemiologie von Arbonematoden wird wesentlich durch die Behandlung mit der Kombination von Diethylcarbamazine oder Ivermectin und Albendazol oder Mebendazol, welche zu einer erheblichen Verminderung der Filaraemie im menschlichen Wirt führt, beeinflusst. Eine Untersuchung auf Wuchereria bancrofti im Norden von Malawi im Jahr 2000/2001 ergab in nachts abgenommenen Blutproben eine Filaraemie bei $31 \%$, eine Hydrocele bei $12 \%$ der Männer und Lymphoedem bei $1 \%$ der Männer und 4\% der Frauen [22]. Von 2000 bis 2003 wurden Gastarbeiter ( $>90 \%$ aus Indien) in Kuwait auf lymphatische Filarien untersucht: es fanden sich mit einem Antigen-Test 18,3\% positiv, mit der Mikroskopie 3\% Filarienträger (Mittelwert 816 Filarien/ml), während keiner Malaria hatte [23]. Proben von Patienten aus Risikoländern für Filarien-Infektionen mit typischen klinischen Symptomen wurden in USA von 1999 bis 2009 mit konventionellen parasitologischen Methoden, einschließlich Blutfiltration, und einer NAT (real time PCR) untersucht. Für Wuchereria bancrofti wurde über die PCR eine Prävalenz von etwa $4 \%$, für Loa loa von etwa $11 \%$ gefunden, während bei der Hautbiopsie (skin snip) um Onchocerca volvulus zu erkennen, die konventionelle Mikroskopie eine Prävalenz von etwa $1 \%$, aber die PCR eine von 6\% ergab.

Die gleichzeitige Gabe von Diethylcarbamazin und Albendazol gegen den Wuchereria bancrofti-Befall führte in einer Studie in Brasilien nach einem Jahr zu keiner stärkeren Reduktion der Mikrofilarienzahl und der Wurmnester [24]. Die zehnmalige Gabe von Diethylcarbamazin führte in Indien zu einer Reduktion von Wuchereria bancrofti Mikrofilarien von über $90 \%$, die neunmalige $\mathrm{Ga}$ be von Ivermectin von etwa 85\% [25]. Die Kombination von Ivermectin und Albendazol war in einer Metaanalyse effizienter gegen Wuchereria bancrofti Mikrofilarien, auch wenn in anderen Studien die Kombination mit Diethylcarbamazin überlegen war [26]. In einer weiteren Analyse aus Sri Lanka war die Gabe von Diethylcarbamazin überlegen, da Ivermectin zwar eine hohe microfilaricide Wirkung, aber nur eine sehr geringe makrofilaricide Wirkung hat [27]. Doxycyclin 
verringert den Mikrofilarien-Befall [27], ebenso Rifampicin [8].

Die einmalige Gabe von Ivermectin pro Jahr führte nach 6 Jahren in Nigeria zu einer Reduktion der MikrofilarienPrävalenz von Onchocerca von $70 \% \mathrm{zu}$ $40 \%$ [28]; in Kamerun und Uganda nach 10 Jahren von 70\% auf 7\% [29], in Äquatorialguinea nach 8 Jahren von $75 \%$ auf $38 \%$, wobei dort große Unterschiede zwischen zwei Volksstämmen und zwischen einzelnen Gemeinden bestanden [30]. Eine andere Studie aus Ghana berichtet bei einer allgemeinen Reduktion des Mikrofilarien-Befalls von einer Verdopplung der Onchocerca-Mikrofilarien Prävalenz in zwei Gemeinden, die auf Resistenz gegen Ivermectin zurückgeführt wurde [31]. Alter, Geschlecht und hyperendemisches Vorkommen von Onchcerca sind weitere Faktoren, die die Effizienz der Ivermectin Behandlung beeinflussen [16].

In Indien wurde das Blut von 119 Schwangeren auf Vorhandensein von Mikrofilarien von Wuchereria bancrofti und deren Antigen (Og4C3) und nach Entbindung das Nabelschnurblut der Neugeborenen untersucht: Mikrofilarien wurden bei $12 \%$ und Antigen bei $44,5 \%$ in mütterlichem Blut gefunden, nur 24,5\% der Neugeborenen der Antigen-positiven Mütter waren Antigen-positiv. Es wurde die Schlussfolgerung gezogen, dass der diaplazentare Antigentransfer für eine frühe Sensibilisierung der Kinder verantwortlich ist [32].

\section{Meldepflicht}

Nach Infektionsschutzgesetz besteht keine Meldepflicht für den Nachweis oder die Erkrankung mit Arbonematoden.

\subsection{Nachweisverfahren und Aussagekraft}

\section{Mikroskopischer Nachweis}

Bis der adulte Wurm ausreichend Mikrofilarien produziert, sodass sie im mikroskopischen Präparat erkannt werden, vergehen etwa 1,5 Jahre [20].

- Nativ-Präparat: Mikrofilarien reichern sich nach Zentrifugation von antikoaguliertem Venenblut an der Grenzschicht von korpuskulären Anteilen und Plasma (buffy coat) an. Bewegliche Mikrofilarien sind unter dem Mikroskop leicht zu erkennen (• Abb. 5), eine Differenzierung ist mit dieser Methode nicht möglich [33].

- Anreicherung im dicken Tropfen: Nach Anfärben mit HaematoxylinEosin-Lösung des lysierten Erythrozyten-Tropfens können Mikrofilarien erkannt, jedoch kaum differenziert werden.

- Anreicherung durch Zentrifugation: Nach Lyse der Erythrozyten und Ausstrich des Sediments und Anfärbung, oder nach Dichtegradienten-Zentrifugation [34] können Mikrofilarien aus einer größeren Blutmenge angereichert werden.

- Anreicherung durch Filtration von Blut nach Lysieren der Erythrozyten an $5 \mu \mathrm{m}$ Polycarbonatfilter und nachfolgender Färbung [33]. Mikrofilarien haben eine Größe um 150-300 $\mu \mathrm{m}$ : Wuchereria bancrofti: die Mikrofilarie trägt eine Kopfscheide (sheath), das Schwanzende ist ohne Kerne; Brugia malayi: die Mikrofilarie trägt eine Kopfscheide, das Schwanzende enthält 1-3 kleine Kerne; Loa loa: die Mikrofilarie trägt eine Kopfscheide, das Schwanzende hat mehrere Kerne; Onchocerca volvulus: die Mikrofilarie ist ohne Kopfscheide, das Schwanzende ist spitz zulaufend und ohne Kerne; Mansonella perstans: die Mikrofilarie ist kleiner (etwa $200 \mu \mathrm{m}$ ), das Schwanzende ist abgerundet (Angelhaken) und enthält Kerne [33].

Hautbiopsie (Hautstanze, skin snip) und Feinnadel-Punktion: an stark juckenden Stellen wird die Haut punktiert und das Biopsat in Kochsalzlösung auf einen Objektträger unter das Mikroskop gelegt. Nach kurzer Zeit wandern Mikrofilarien, besonders die von Onchocerca, aus und sind im Mikroskop zu erkennen.

\section{Antikörper-Nachweis}

Ein Schnelltest für den Nachweis von Onchocerca IgG4-Antikörper, der als Antigen die Glutathion-S-Transferase (Ov16) enthielt, zeigte bei der Untersuchung von 106 infizierten Patienten eine Sensitivität von $91 \%$ und eine Spezifität von $95 \%$. Eine Kreuzreaktion mit anderen FilarienInfektionen besteht [35]. Basierend auf 4
Antigenen von Onchocerca volvulus mit dem Format eines Luciferase-Immunpräzipitations-Systems (LIPS) wurde in Onchocerca-Infizierten eine $100 \%$ Sensitivität und 100\% Spezifität gefunden [36]. Ein ähnlich konfigurierter Test für den Nachweis von Loa loa-Antikörper erreichte eine Sensitivität von 67\% und eine Spezifität von 99\%; Kreuzreaktionen bestanden mit Onchocerca volvulus, Mansonella perstans und Wuchereria bancrofti [37]. Ein dipstick-chromatographischer Test für den Nachweis einer Infektion mit Brugia zeigte eine Sensitivität zwischen $61 \%$ und $97 \%$ bei einer Spezifität von $100 \%$, für Onchocerca volvulus eine Spezifität von 99\% und Loa loa von 85\% [38].

\section{Antigen-Nachweis}

Ein Og4C3-Test zum Nachweis von Wuchereria bancrofti-Antigen aus eingetrocknetem Fingerbeerenblut zeigte eine 100\% Sensitivität und 94\% Spezifität und war somit der Mikroskopie überlegen [39]. Mit Hilfe des Og4C3-Antigen ELISA, als Indikator für die Besiedelung mit adulten Würmern, fanden Bal et al (2009) [40] unter Kindern in Indien bei nächtlicher Blutabnahme eine Prävalenz von $32 \%$, während die mikroskopisch nachweisbare Mikrofilariaemie nur bei 10\% lag. Rocha et al (2009) [41] verglichen die Sensitivität zweier Antigen-Tests (Og4C3-ELISA und AD12-ICT card test) für zirkulierendes Antigen von Wuchereria bancrofti (nachts genommene Proben) mit der Ultraschall-Analyse zum Erkennen des Befalls mit adulten Würmern. Mit den Antigen-Tests wurde eine Sensitivität von $97 \%$ erreicht, mit der Ultraschallmethode eine von $73 \%$.

\section{Genom-Nachweis (NAT)}

Arbonematoden in menschlichem Blut, Gewebe oder Vektor nachzuweisen gelingt am empfindlichsten mit der Amplifikation von Nematoden-Nukleinsäure. Ziel ist 1 Mikrofilarie pro $\mathrm{ml}$ nachzuweisen. Als genomische Region wurde die Ssp1 DNA repeat Sequenz von Wuchereria bancrofti amplifiziert [42; 43] und in nächtlich entnommenen Blutproben

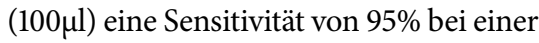
Spezifität von $100 \%$ erreicht. In am Tage entnommenen Proben war die Sensitivität mit 70\% geringer [43]. 


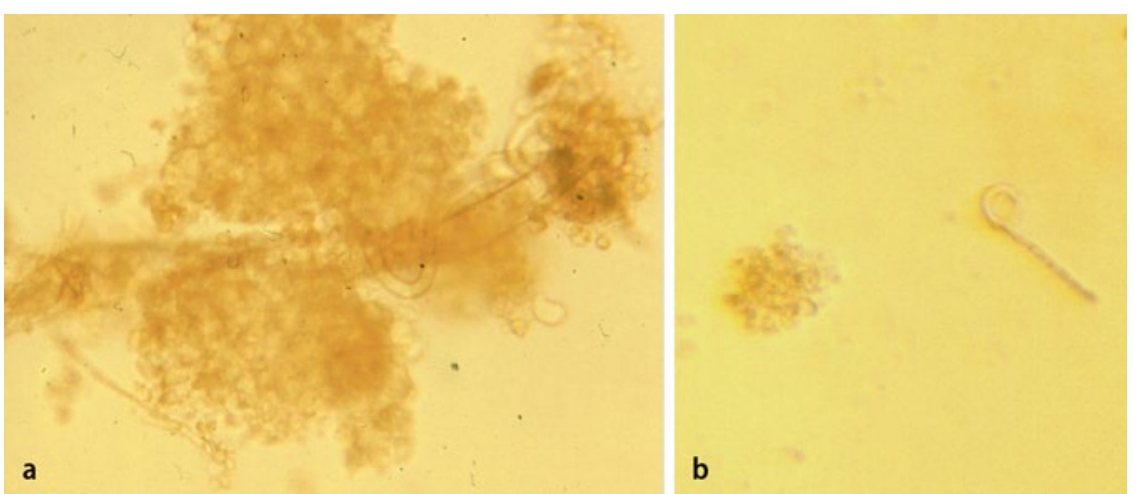

Abb. $5 \Delta$ a Fünf Mikrofilarien, sich teils an eine Baumwollfaser anheftend, im Nativ-Präparat nach Anreicherung über Ficoll-Paque Gradienten-Zentrifugation. Die Zellklumpen bestehen aus Lymphozyten und Makrophagen mit einem mittleren Durchmesser von $7 \mu \mathrm{m}$.

b Singuläre Mikrofilarie, links davon Lymphozyten-Aggregat (Quelle: Prof. Dr. L. Gürtler).

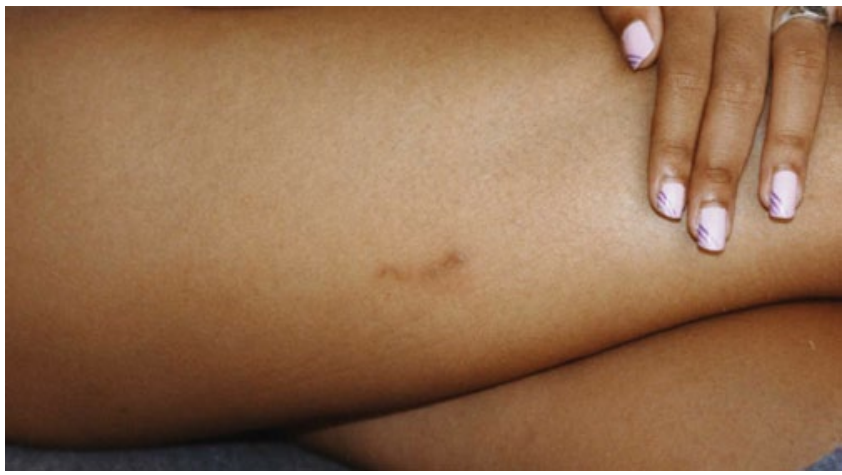

Durch Amplifikation einer 320 bp Sequenz (HhaI repeat DNA) von Brugia malayi über eine real-time PCR (Taqman PCR) oder des Minor Groove Binder (MGB) Tests wurden 22.000 Kopien mit der Taqman-PCR bzw 22 Kopien repeatDNA mit der MGB nachgewiesen. Beide Nachweisverfahren waren negativ für Brugia pahangi (in Affen vorkommend) und Wuchereria bancrofti Mikrofilarien [44]. Eine Einschritt multiplex PCR für den gleichzeitigen Nachweis von Brugia malayi und Wuchereria bancrofti Ssp I repeat DNA wurde von Mishra et al, 2007 [45] entwickelt. Der Test war empfindlicher als die Mikroskopie und erreichte eine Sensitivität von 1 Mikrofilarie pro $100 \mu$ l Blut. Mit einer nested PCR konnte zwischen einer Infektion mit Filarien von Onchocerca volvulus, Mansonella ozzardi und Mansonella perstans unterschieden werden [46].

Eine multiplex realtime PCR für den gleichzeitigen Nachweis von Wuchereria bancrofti, Plasmodium falciparum und Plasmodium vivax DNA in Anopheles Mücken wurde für epidemiologische
Abb. $6<$ Abgestorbene, subcutan liegende Loa loa Mikrofilarie. Klinisch imponiert nur noch die Induration und Hyperpigmentierung. Mit Erlaubnis von: Dr. R. Krippner, Deutsche Botschaft, Yaounde, Kamerun 2006.

\section{Blut- und Plasmaspender}

\subsection{Prävalenz und Inzidenz bei Spenderkollektiven}

Für Deutschland liegen hierzu keine Publikationen vor. Touristen, die sich länger in Endemiegebieten aufgehalten haben, können nach Mücken- oder Bremsenstich und einer Entwicklungszeit der adulten Würmer von 6 Monaten und länger Träger von Mikrofilarien sein. Die Entwicklungszeit und Pathogenese ist unter 1.2 beschrieben. Die Wahrscheinlichkeit eines Trägertums liegt unter 2\% [51].

Unter spanischen Tropenrückkehrern aus Ländern südlich der Sahara hatten 1,7\% eine Filaria-Besiedlung [51]. In USA fiel 1978 bei einem Mehrfach-Blutspender eine Mansonella ozzardi-Infektion auf, die während einer Reise in die Karibik erworben wurde; das Risiko Mikrofilarien durch Reise in einem Endemiegebiet zu erwerben wird von den $\mathrm{Au}$ toren mit 1 in 500 angegeben [52]. Eine Filariose-Infektion wurde bei $271(0,62 \%)$ von etwa 44.000 untersuchten Reiserückkehrern nachgewiesen, besonders dann, wenn sie sich länger als 1 Monat in der tropischen Heimatregion aufgehalten hatten. Von diesen 271 Untersuchten hatten 37\% eine Onchocerca-, 25\% eine Loa loa-, und $25 \%$ eine Wuchereria bancrofti-Infektion, der Rest hatte andere Filarien [53]. Nach Angabe des Instituts für Tropenmedizin der Universität München werden dort pro Jahr bei etwa 20 Personen, Immigranten und Reiserückkehrer aus Westafrika, Mikrofilarien nachgewiesen (Prof. Dieter Notdurft, persönliche Mitteilung).

Nach Ende des zweiten Weltkriegs ist in Deutschland über eine durch Transfusion erworbene Mikrofilarien-Infektion nicht berichtet worden; in USA nur von einem Fall [54].

\subsection{Definition von \\ Ausschlusskriterien} Sensitivität der Mikroskopie auch in erfahrenen Labors überlegen [50].

Die Rückstellung von Tropenrückkehrern wegen des Risikos einer Malaria-Infektion für 6 Monate ist kein ausreichendes Ausschlusskriterium für eine mögliche Übertragung von Mikrofilarien, da sich eine Filaraemie erst später entwickeln kann (siehe unter 1.2). Typische Symptome einer 
Filarien-Besiedlung sind Juckreiz an der Haut und intermittierende Sehstörungen. Spender mit entsprechender Reiseanamnese und den beschriebenen Symptomen sollten von der Spende solange zurückgestellt werden, bis eine Laboranalyse eine Besiedlung mit Mikrofilarien ausgeschlossen hat.

\subsection{Spendertestung und Aussagekraft}

Eine Testung der Spender auf Mikrofilarien mit einer sensitiven PCR ist möglich, ist aber bei der niedrigen Inzidenz nicht gerechtfertigt.

\subsection{Spenderbefragung}

Eine spezifische Befragung des Spenders zur Reiseanamnese und dem Infektionsrisiko mit Filarien findet nicht statt, ist auch wegen der niedrigen Prävalenz und Inzidenz nicht notwendig.

\subsection{Spenderinformation und Beratung}

Information und Beratung führen die tropenmedizinischen Institutionen, andere infektiologische Zentren und Spezialambulanzen für Tropenmedizin durch.

\section{Empfänger}

\subsection{Prävalenz und Inzidenz von \\ Blut-assoziierten Infektionen \\ und Infektionskrankheiten \\ bei Empfängerkollektiven}

Über Prävalenz und Inzidenz liegen keine Publikationen für Deutschland vor. Wie unter den Rückkehrern aus Endemieregionen erwähnt (siehe 2.1), können auch Empfänger nach Aufenthalt in Endemiegebieten vor einer Bluttransfusion mit Filarien infiziert sein.

\subsection{Abwehrlage (Resistenz, vorhandene Immunität, Immunreaktivität, Alter, exogene Faktoren)}

Mikrofilarien können in jedem Alter durch Stich des infizierten Vektors erworben werden. Geringe Mengen an L1-Mi- krofilarien, wie sie z. B. in einer Blutkonserve vorhanden sein könnten und dann übertragen würden, werden durch die Abwehrreaktionen der natürlichen Immunität (innate immunity) aus der Blutbahn entfernt [54].

\subsection{Schwere und Verlauf der Erkrankung}

Die iv-Übertragung von L1-Mikrofilarien auf einen Menschen (Selbstversuch von Gönnert und artifizielle Infektion von Patienten) führte nach 16-24 h zu Müdigkeit, Mattigkeit, Kopfschmerzen und Fieberanstieg bis $>39^{\circ} \mathrm{C}$ für einige Tage; begleitet war die febrile Reaktion von einer Eosinophilie [55; 56]. Während die L1-Mikrofilarien von Wuchereria bancrofti innerhalb weniger (4-5) Tage aus dem Blut eliminiert wurden [56], verblieben die L1-Mikrofilarien von Mansonella perstans bis zu 37 Monate im Empfänger, ohne Symptome zu verursachen [55]. In einer anderen Studie waren nach iv Injektion $\mathrm{Wu}$ chereria bancrofti Mikrofilarien in Menschen nach 12-18 Tagen im Blut nicht mehr nachweisbar, wurden sie Mäusen iv injiziert, waren sie schon nach $40 \mathrm{~h}$ aus der Blutbahn eliminiert, nach ip und sc Injektion in Mäuse oder Ratten überlebten sie 14 Tage [57].

Nach Übertragung von L3-Larven der Filarien durch den Vektor auf den Menschen können Jahre vergehen bis sich eine typische Symptomatik zeigt (siehe unter 1.2 Pathogenese). Als erstes Symptom treten allergische Reaktionen auf, die sich besonders mit Juckreiz und teils starken Schmerzen bei Befall der Augen äußern, in der Haut bilden sich Wurmkonvolute, die tastbar und sichtbar sind; nach vielen Jahren tritt Entzündung und Weitstellung der Lymphgefäße und die nachfolgende Elephantiasis auf. Das Absterben des adulten Wurms kann durch die Freisetzung von Wolbachia starke Entzündungsreaktionen auslösen. Durch Gabe von Doxycyclin, und Diethylcarbamazin oder Ivermectin und Albendozol/Mebendazol ist die Krankheit nach mehreren Therapiezyklen heilbar (siehe unter 3.4).

\subsection{Therapie und \\ Prophylaxemöglichkeiten}

\section{Chemotherapie}

Doxycyclin, Diethylcarbamazin, Ivermectin und Albendazol stehen gegen die Mikrofilarien und die Würmer zur Verfügung, wobei Ivermectin keine Wirkung gegen Makrofilarien hat und Albendazol nur gegen den adulten Wurm wirkt. Die lebenswichtige Symbiose von Wuchereria, Brugia und Onchocerca mit dem Bakterium Wolbachia wird durch Tetrazyclin (Doxycyclin), Rifampicin oder Azithromycin eingeschränkt, bzw. unterbunden $[58 ; 10 ; 8]$. Doxycyclin vermindert signifikant die Freisetzung von VEGF (vascular endothelial growth factor) und die Dilatation der lymphatischen Gefäße [15] (siehe unter 1.2 Pathogenese).

Ziel der Therapie ist, die klinischen Symptome wie Lymphoedem, Hydrocele und Elephantiasis zu verhindern und epidemiologisch durch die verminderte $\mathrm{Mi}$ krofilarien-Produktion die Transmission der Filarien einzuschränken.

Wuchereria bancrofti, Brugia malayi, Brugia timori (lymphatische Filarien) und Onchocerca volvulus, Mansonella perstans. Die Therapie startet mit Doxycyclin $(200 \mathrm{mg} / \mathrm{d})$ für 4-6 Wochen, dann wird eine einmalige Dosis von Diehthy carbazamin $(6 \mathrm{mg} / \mathrm{kg})$ plus Albendozol (400 mg) gegeben; wenn Onchocercerca gleichzeitig mit Wuchereria vorhanden ist, was in vielen Regionen zutrifft, Ivermectin $(200-400 \mu \mathrm{g} / \mathrm{kg})$ plus Albendozol (400 mg) [8; 59]. Das Therapieregime wird jährlich für 5 Jahre wiederholt und der Erfolg der Therapie über die Zahl der Mikrofilarien in Blut und Gewebe kontrolliert. Durch Kontrolle und Reduktion der Verbreitung des Vektors sollte innerhalb des Jahres eine Reinfektion vermieden werden. Bei Kindern über 10 Jahren und bei Schwangeren, wenn überhaupt, wird derzeit nur die Behandlung mit Doxycyclin (cave Zahn- und Knochenaufbau-Schädigung) empfohlen.

Die Effizienz der Doxycylin-Behandlung gegen Mansonella perstans war in Mali mit einem Absinken der Mikrofilarienzahl im Blut nach 6 Monaten auf etwa $23 \%$ und nach 12 Monaten auf $0 \%$ sehr hoch [59], während in der unbehan- 
delten Kontrollgruppe nach 6 Monaten ein Abfall auf $62 \%$ und nach 12 Monaten auf $50 \%$ gemessen wurde. Die 12 Monate Effektivität der Doxycyclin-Behandlung war 97\% (67 von 69 Behandelten), im Vergleich zu keiner Behandlung mit 16\% (10 von 63) und zu Ivermectin-Albendazol mit 19\% (5 von 27) [59].

Nebenwirkungen sind: Fieber, Kopfschmerz, Juckreiz und Myalgie, die besonders in Regionen, wie z. B. Kamerun, hoch sind, wo Loa loa gleichzeitig endemisch ist. Schwere Nebenwirkungen mit progressivem Verlust von neurologischen Funktionen und Enzephalopathie trat bei 1 in 800.000 Behandelten auf [8]. Die Doxycyclin-Vorbehandlung verhindert das Auftreten von akuten Entzündungsreaktionen, wie der akuten Dermatolymphangioadenitis. Eine häufige Nebenwirkung der Doxycylin-Behandlung ist Erbrechen [59]. Die Nebenwirkungen der Diethylcarbazamin-Therapie waren umso größer, je höher die Anzahl der Mikrofilarien im Gewebe war und je mehr Interleukin-6 und Lipopolysaccharid-bindendes Protein freigesetzt wurde [60].

Loa loa. Diethylcarbamazin hat nur eine Wirkung gegen den adulten Wurm. Die Gabe führt zum Absterben der Würmer mit einer teils massiven Herxheimer-Reaktion, die begleitet sein kann von schweren Nebenwirkungen, wie Enzephalopathie, die teils tödlich verläuft, und über Mikroembolien in den Kapillaren des Gehirns induziert wird [10]. Therapieempfehlung ist heute eine einmalige Gabe von Ivermectin, $50-200 \mu \mathrm{g} / \mathrm{kg}$ plus Albendazol (400 mg), die nach Monaten wiederholt werden kann. Unter der Kombination Ivermectin/Albendazol sind schwere Nebenwirkungen selten, in Patienten mit einer Mikrofilarienbelastung von $<8.000$ / $\mathrm{ml}$ treten sie kaum auf.

Die allergischen Nebenwirkungen können mit der Gabe von Cortison unterdrückt werden. Eine simultane Tetracyclin-Gabe erübrigt sich, da in Loa loa keine Wolbachia vorhanden sind $[7 ; 10]$. Moxidectin, welches starke Wirksamkeit gegen Makrofilarien zeigt, könnte als neues Medikament in die Therapie Eingang finden [61]. Abb. 6 zeigt eine abgestorbene Mikrofilarie in der Haut, sog. Larva migrans, bei einer Frau in Kamerun.

\section{Prophylaxe vor Arthropoden- stichen Behandlung der Brutstätten des Vektors}

DDT (Dichlor-diphenyl-trichlorethan) wird wegen der neurologischen Nebenwirkung beim Menschen und Resistenz einiger Mückenarten nicht mehr empfohlen. In menschennahen Behausungen wird empfohlen, freie Wasseroberflächen, einschließlich der offenen Latrinen, mit Polystyrol (Styropor)-Kügelchen abzudecken, sodass die sich entwickelnden Mückenlarven ersticken. Durch diese Maßnahme konnte in einer Gemeinde die Stichrate von etwa 25.000 pro Jahr auf etwa 500 gesenkt werden [62]. Sehr wirksam ist weiterhin das Trockenlegen aller potentiellen Brutstellen für Mücken.

Mückenstichprophylaxe. Das Vermeiden von Mückenstichen ist die effizienteste Prophylaxe. In vielen Regionen, in denen auch Arboviren übertragen werden, werden simultan Plasmodien und Mikrofilarien über Mücken übertragen [13]. Anopheles sticht in der Dämmerung, diese dauert in Afrika von 4:00 bis 6:30 und 16:00 bis 18:30. Culicoides sind tagund nachtaktiv, Culex und Aedes nachts aktiv.

Bremsenstichprophylaxe. Bremsen stechen tags, sie warten an schattigen Plätzen auf Stechgelegenheit. Tiere einschließlich Affen ziehen Bremsen an, so sollten diese Areale gemieden werden. Helle Kleidung vermindert die Attraktivität für Bremsen. Der Stich der Bremsen ist sehr schmerzhaft und wird deswegen bemerkt.

Kriebelmückenstichprophylaxe. Habitat sind die Galeriewälder in den Savannen und die Umgebung von schnell fließenden Bächen/Flüssen im Regenwald. Die Kriebelmücke kommt in Schwärmen vor, hält sich im Schatten von Bäumen auf und ist aggressiv tagaktiv. Die Larven entwickeln sich an fließenden Wasserstellen, die eine hohe Sauerstoffkonzentration haben, d. h. normalerweise offene Strömung zeigen. Wirt für die Kriebelmücken sind häufig Tiere und Menschen, sodass ein humaner Kreislauf entstehen kann, der jedoch über Therapie der betroffenen Population mit Ivermectin und Albendazol unterbrochen werden kann. Der Stich der Kriebelmücke ist ausgesprochen schmerzhaft. Kriebelmückenlarven können teilweise noch durch das Toxin von Bacillus sphaericus oder B. thuringiensis abgetötet werden, aber BacillusToxin resistente Mückenlarven haben sich in Westafrika entwickelt [63].

Impfung. Impfung von asiatischen Wüstenmäusen (jirds, Rennmaus, ähnlich Gerbils) mit einem rekombinanten Protein aus Maltose-bindenden-Protein (BM5MBP) und Paramyosin von L3-Larven von Brugia malayi führte nach zweimaliger Applikation zu einer Immunität, sodass nach Infektion mit 100 L3-Larven die Zahl der auswachsenden adulten Würmer vermindert und diese kleiner waren [64]. Immunisierung von Balb/c Mäusen und asiatischen Rennmäusen mit Maltosebindendem-Protein gekoppelt an Tropomyosin von Onchocerca volvulus ergab nach Infektion mit Mikrofilarien eine etwa $45 \%$ Reduktion des Wachstums der adulten Würmer [65]. Tropomyosin von Onchocerca volvulus zeigt in der Aminosäure-Zusammensetzung eine $91 \% \mathrm{Ho}$ mologie mit dem anderer Nematoden; deswegen wurde dieses Antigen zur Immunisierung von Mäusen verwendet. Die Immunität gegen Mikrofilarien war an die Bildung von IgE gebunden und konnte auf andere Mäuse übertragen werden [66].

Eine zelluläre Immunantwort gegen Loa loa wurde in Mandrills ausgelöst, die mit 50 bestrahlten L3-Larven immunisiert wurden. Die geimpften Tiere zeigten eine Th1-Antwort gegen L3, während nicht-geimpfte Tiere eine Th2-Antwort hatten. Nach Infektion mit 100 lebenden L3-Mikrofilarien zeigten einige Tiere keine Mikrofilaraemie, was als Schutzwirkung gewertet wurde [67]. Eine Impfung von Mandrills mit 150 bestrahlten L3-Larven und artefizieller Infektion 60 Tage später ergab anfangs keinen Unterschied zu nicht-geimpften Mandrills. Erst nach 245 Tagen hatten die geimpften Mandrills eine wesentlich geringere Mikrofilaraemie [68]. Ratten und Rennmäuse wurden mit rekombinantem Brugia malayi Myosin (Molekulargewicht 73 $\mathrm{kDa})$ dreimal immunisiert. Nach artifizieller Infektion mit 100 Larven eine Woche nach der letzten Impfung zeigten die 
vaccinierten Tiere eine Reduktion der Mikrofilarienmenge im Blut um 76\% gegenüber den Kontrolltieren und der Wurmbelastung um etwa 50\% [69].

Die Versuche zeigen, dass über Impfung ein gewisser Grad an Immunität erreicht werden kann, sie legen jedoch nahe, dass ein humaner Impfstoff in naher Zukunft nicht zur Verfügung stehen wird. Die Prävention der Mikrofilarienübertragung durch jährliche Gabe von Diethylcarbamazin oder Ivermectin und Albendazole oder Mebendazol in Endemiegebieten ist das wirksamere Verfahren eines Schutzes [31].

\section{5 Übertragbarkeit}

\section{Bluttransfusion}

In ACD-Blut überlebten L1-Mikrofilarien von Wuchereria bancrofti bei $4-6^{\circ} \mathrm{C}$ für 12 Tage in gut beweglichem Zustand, nach 21 Tagen waren sie unbeweglich, konnten aber durch Erwärmung reaktiviert werden, und nach 25 Tagen waren sie abgestorben [70]. In Citrat-Blut bei $4^{\circ} \mathrm{C}$ aufbewahrte Mikrofilarien von Wuchereria bancrofti überlebten wenigstens 39 Tage, von Brugia malayi 47 Tage und von Loa loa 15 Tage [71]. Etwa ein Drittel der Mikrofilarien von Loa loa überlebten für 21 Tage in ACD-Blut in einer anderen Studie [54]. Folglich können in der Blutspende enthaltene Mikrofilarien bis zur Transfusion theoretisch überleben.

Eine Übertragung einer Filariose durch Transfusion findet, auch wenn L1Mikrofilarien transfundiert werden [70], dennoch nicht statt, da die weitere Reifung zu L3-Mikrofilarien nur im Vektor und nicht im Menschen abläuft (siehe 1.2).

Mansonella perstans Filarien, die durch Transfusion übertragen wurden, wurden schnell aus dem Blut des Empfängers eliminiert, ohne dass es zum Auftreten von Symptomen oder einer Eosinophilie nach 4 Monaten kam [72; 73]. Andererseits beschrieben Gönnert und auch Nutman, dass M. perstans Mikrofilarien im Empfänger bis zu 3 Jahre nach Transfusion nachweisbar waren $[55 ; 74]$.

In einer Analyse zur Übertragung von Mikrofilarien über Bluttransfusion in Indien wurden die Empfänger von 11.572 Transfusionen für 15 Monate nachunter- sucht. 5 der Spender waren Filarienträger, 4 der Empfänger wurden infiziert und in 2 der Empfänger und der Spender waren Filarien im gesamten Untersuchungszeitraum nachweisbar. Die Schlussfolgerung war: Auch wenn die Übertragung der Mikrofilarien nicht zur Ausbildung des adulten Wurmes führt, sollten Blutspender mit bekannter Filarien-Infektion von der Spende ausgeschlossen werden [75].

In USA übertrug die Transfusion von einem regulären Spender Mansonella ozzardi nach Ferienaufenthalt in der Karibik [52], wie unter 1.3 und 2.1 erwähnt.

\section{Plasma}

Eine Übertragung von Mikrofilarien über FFP (fresh frozen plasma) ist ausgeschlossen, da Mikrofilarien den Frier-Tau-Zyklus nicht überleben.

\section{Stichverletzung}

Bisher wurde keine Übertragung von $\mathrm{Mi}$ krofilarien durch Stichverletzung bei medizinischem Eingriff oder durch Nadelstichverletzung berichtet.

\subsection{Häufigkeit und Menge der Applikation der Blutprodukte}

Fresh frozen plasma (FFP) ist für Filarien nicht infektiös, da die Parasiten beim Frier-Tau-Vorgang abgetötet werden (siehe 3.5).

Erythrozyten-Konzentrat: Über Häufigkeit und Menge kann keine Aussage gemacht werden, da für Deutschland keine Zahlen vorliegen. Nachdem L1-Larven 6 Wochen bis 37 Monate im Menschen überleben können, ist die Rückstellung von Blutspendern für 6 Monate wegen Malaria nach Tropenaufenthalt nicht ausreichend, um eine Filaraemie mit z.B. Mansonella sicher auszuschließen [76].

Thrombozyten-Konzentrat: Eine Übertragung von Mikrofilarien über Thrombozyten-Konzentrat ist bisher nicht berichtet worden. L1-Larven sollten den Herstellungsprozess überleben, sie führen aber nicht zur Infektion mit dem Wurm, da die weitere Reifung zur L3-Larve unterbleibt.

\section{Blutprodukte}

\subsection{Belastung des \\ Ausgangsmaterials und \\ Testmethoden}

In Endemiegebieten wie Ibadan, Nigeria, hatten 1987 3,5\% der untersuchten 115 Blutspender eine Loa loa Mikrofilariaemie, im Vergleich dazu waren $7,8 \%$ mit Plasmodium falciparum infiziert [77]. Unter 364 Blutspendern in Maiguguri, Nigeria, hatte keiner eine Filarien-Infektion [78]. Unter 1.259 Blutspendern in Ile-Ife, Nigeria, waren $2(0,16 \%)$ MikrofilarienTräger [79]. In der Blutbank eines Krankenhauses mit Maximalversorgung in Bangkok wurde von 1999 bis 2009 keine Filarien-Infektion in Blutspenden nachgewiesen [80].

Prävalenzen in weiteren Endemiegebieten sind unter Epidemiologie 1.3. beschrieben.

Somit ist die Belastung des Ausgangsmaterials mit Mikrofilarien sehr unterschiedlich und wenn überhaupt als sehr gering zu betrachten. Über die NAT-Testung (siehe 1.4 Genomnachweis) könnte eine Mikrofilariaemie in Blutspenden nachgewiesen werden.

\subsection{Möglichkeiten der Abtrennung und Inaktivierung von Infektionserregern}

Mikrofilarien zirkulieren normalerweise extrazellulär im Blut. Durch Filtration über $40 \mu \mathrm{m}$ Blutfilter wurden am Tag 1 der Blutabnahme $80 \%$ von Loa loa Mikrofilarien zurückgehalten, am Tag 21 waren es etwa 92\% [54].

Mikrofilarien im L1- oder L3-Stadium konnten in Medium, welches reduziertes Glutathion, humane Zellen und humanes Serum (spezifische Chargen sind erforderlich) enthielt, am Leben erhalten [81] und für Spike-Versuche verwendet werden. Pflanzliche Extrakte, die die Lebensfähigkeit der Mikrofilarien beeinträchtigen, sind mit dieser Methode getestet worden [82]. Mit hohem Aufwand wären somit Spike-Versuche möglich, um eine Abtrennung oder Inaktivierung zu prüfen.

Eine Inaktivierung von Mikrofilarien ist unter dem Aspekt der Gabe von Plasma oder „Plasmaprodukten“ bisher nicht 
beschrieben worden. Für nicht-zelluläre Blutprodukte reicht ein Einfrier-AuftauVorgang aus, um die Mikrofilarien abzutöten. Bei Kryokonservierung mit 6\% DMSO (Dimethylsulfoxid) und $15 \% \mathrm{Se}$ rum, wie sie für die Aufbewahrung von Stammzellen verwendet wird, sterben nur etwa 6\% der Mikrofilarien ab [83]. Bestrahlung mit Gammastrahlen bis 10,5 Gy (Gray) tötet Mikrofilarien von $\mathrm{Wu}$ chereria bancrofti nicht ab [84]. Behandlung mit $5 \mathrm{mg} / \mathrm{ml}$ Diehtylcarbamazin in vitro löste Mikrofilarien von Wuchereria bacrofti auf [85], Behandlung mit 2 bis $10 \mu \mathrm{M}$ Mefloquine (Lariam ${ }^{\circledR}$ zur MalariaProphylaxe) tötete Mikrofilarien von Brugia malayi nach $10 \mathrm{~h}$ bis 3 Tagen ab [86].

\subsection{Praktikabilität und \\ Validierbarkeit der Verfahren \\ zur Elimination/Inaktivierung \\ von Infektionserregern}

\section{Suszeptibilität im Tierversuch}

Tiere, die experimentell mit Loa loa infiziert werden können, sind Drill (Mandrillus leukophaeus) und Mandrill (Mandrillus sphinx). In Gabon wurden 7 Mandrill mit unterschiedlicher Menge von L3Larven von Loa loa infiziert. In einem mit 1.000 L3-Larven infizierten Tier wurden keine Filarien nachgewiesen, in weiteren 4 bestand eine Filaraemie nach etwa 150 Tagen und in den restlichen 2, deren Mütter mit Mikrofilarien infiziert waren, wurden Filarien erst nach 200 Tagen nachgewiesen. Die Filarienbelastung war unterschiedlich mit bis zu 10.000 Mikrofilarien/ $\mathrm{ml}$, jedoch war nach 300 Tagen in allen 6 Tieren die Menge auf 10-100 Mikrofilarien/ml gesunken. Die Tiere zeigten keine klinischen Symptome, keine Leukocytose und keine Eosinophilie [87]. Folglich steht ein ausreichend valides Tiermodell nicht zur Verfügung.

Antigentest und PCR (siehe 1.4 Nachweisverfahren) sind geeignet um eine $\mathrm{Ab}$ reicherung nachzuweisen, jedoch nicht um restliche Infektiosität auszuschließen.

\section{Bewertung}

Arbonematoden sind in tropischen Regionen mit Regen- und Galeriewäldern weit verbreitet. Sie können in hoher Zahl bei Infizierten vorhanden sein. Filarien werden selten nach Deutschland eingeschleppt und bisher gibt es keine Berichte, dass diese Parasiten über Bluttransfusion in Deutschland übertragen wurden. Wenn überhaupt sind in der Blutspende L1-Larven der Filarien vorhanden, die abhängig von der Menge und Art nach einigen Wochen oder mehreren Monaten im neuen menschlichen Wirt absterben und nicht zum Wurm ausreifen können. Insofern wäre das Übertragen der Mikrofilarien über Bluttransfusion ein selbstlimitierendes Ereignis und macht keine weiteren Maßnahmen zum Schutz des Empfängers erforderlich.

$\mathrm{Ob}$ sich im Laufe der Klimaerwärmung die Prävalenz von Mikrofilarien in den Vektoren Mücke und Bremse erhöht und eine Übertragung auf den Menschen wahrscheinlicher macht, sollte beobachtet werden. Als nicht-menschliche Wirte sind für Brugia asiatische Primaten und Katzen, und für Loa loa afrikanische Primaten bekannt, die aus epidemiologischer Sicht für einen Übertragungszyklus in Deutschland unbedeutend sind.

Ein routinemäßiges Testen auf Mikrofilarien oder eine Ausweitung der Reiserückstellung von Blutspendern ist nicht erforderlich

Dieses Papier wurde fertig gestellt am 22.11.2011 und vom Arbeitskreis Blut am 30.03.2012 verabschiedet. Es wurde erarbeitet von den Mitgliedern der Untergruppe „Bewertung Blut-assoziierter Krankheitserreger" des Arbeitskreises Blut:

Prof. Dr. Lutz Gürtler, Dr. Ursula Bauerfeind, Dr. Johannes Blümel, Prof. Dr. Reinhard Burger, Prof. Dr. Christian Drosten, Dr. Albrecht Gröner, Dr. Margarethe Heiden, Prof. Dr. Martin Hildebrandt, Prof. Dr. Dr. Bernd Jansen, Dr. Thomas Montag-Lessing, Dr. Ruth Offergeld, Prof. Dr. Georg Pauli, Prof. Dr. Rainer Seitz, Dr. Uwe Schlenkrich, Dr. Volkmar Schottstedt, Dr. Johanna Strobel, Dr. Hannelore Willkommen.

\section{Literatur}

1. Blümel J, Burger $R$, Gerlich $W$, Gürtler $L$, Heiden $M$, Hitzler W, Jansen B, Klamm H, Lefèvre H, Ludwig WD, Montag-Lessing T, Offergeld R, Paessens A, Pauli G, Seitz R, Schlenkrich U, Schottstedt V, Willkommen $\mathrm{H}$, Baljer $\mathrm{G}$. Coxiella burnetii - Pathogen of the Q (Query) fever. Transfus Med Hemother 2005; 32: 218-226

2. Blümel J, Burger R, Drosten C, Gröner A, Gürtler L, Heiden M, Hitzler W, Jansen B, Klamm H, Ludwig WD, Montag-Lessing T, Offergeld R, Pauli G, Seitz $\mathrm{R}$, Schlenkrich U, Schottstedt V, Willkommen H. Arbobakterien (über Arthropoden übertragbare Bakterien). Bundesgesundheisbl. Gesforsch. Gesschutz. 2007; 50: 1192-1207

3. Gürtler $L$, Blümel J, Burger R, Drosten C, Gröner A, Heiden M, Hildebrandt M, Jansen B, MontagLessing T, Offergeld R, Pauli G, Seitz R, Schlenkrich U, Schottstedt V, Strobel J, Willkommen H, Wirsing von König $\mathrm{CH}$. Arboprotozoen. Bundesgesbl Gesundforsch Gesundschutz 2009; 52 : 123-146

4. Maguire JH. Introduction to helminth infections. In Mandell, Douglas, Benett's Principles and Practice of Infectious Diseases, 7th edition, 2010, Churchill Livingstone, Philadelphia, pp 35733575

5. Kazura JW. Tissue nematodes, including Trichinellosis, Dracunculiasis and the Filariases. In Mandell, Douglas, Bennett's Principles and Practice of Infectious Diseases. 7th edition, 2010, Churchill Livingstone, Philadelphia, pp 3587 3594

6. Peeters W, Gilles HM. Colour Atlas of Tropical Medicine and Parasitology, 3rd edition, 1989, Wolfe Med Pub, London, pp 65-82

7. Taylor M, Hoerauf A, Backarie M. Lymphatic filariasis and onchocerciasis. Lancet 2010; 376: 1175-1185

8. Bockarie MJ, Taylor MJ, Gyapong JO. Current practices in the management of lymphatic filariasis. Expert Rev Anti Infect Ther 2009; 7: 595605

9. Arumugam S, Pfarr KM, Hoerauf A. Infection of the intermediate mite host with Wolbachia-depleted Litomosoides sigmodontis microfilariae: impaired L1 to L3 development and subsequent sex-ratio distortion in adult worms. Int J Parasitol 2008; 38: 981-987

10. Boussinesq M. Loiasis. Ann Trop Med Parasitol 2006; 100: 715-731

11. Dzamic AM, Colovic IV, Arsic-Arsenijevic VS, Stepanovic S, Boricic I, Dzamic Z, Mitrovic SM, Rasic DM, Stefanovic I, Latkovic Z, Krajcic-Zec IF. Human Dirofilaria repens infection in Serbia. J Helminthol 2009; 83: 129-137

12. Panaitescu D, Freda A, Bain O, Vasile-Bugarin AC. Four cases of human filariosis due to Setaria labiatopapillosa found in Bucharest, Romania. Roum Arch Microbiol Immunol 1999; 58: 203207

13. Manguin S, Bangs MJ, Pothikasikorn J, Chareonviriyaphap T. Review on global co-transmission of human Plasmodium species and Wuchereria bancrofti by Anopheles mosquitoes. Infect Genetic Evolution 2010; 10: 159-177

14. Grove DI. Tissue nematodes including trichinosis, dracunculiasis, and the filariasis. In Mandell, Douglas, and Bennett's Principles and Practice of Infectious Diseases, 6th edition, Elsevier Churchill Livingstone, Philadelphia, 2005, pp 32673276 
15. Debrah AY, Mand S, Toliat MR, Marfo-Debrekyei Y, Batsa L, Nürnberg P, Lawson B, Adjei O, Hoerauf A, Pfarr K. Plasma vascular endothelial growth factor A (VEGF-A) and VEGF-A polymorphism are associated with hydrocele development in lymphatic filariasis. Am J Trop Med Hyg 2007; 77: 601-608

16. Pion SD, Grout L, Kamgno J, Nana-Djeunga $H$, Boussinesq M. Individual host factors associated with Onchocerca volvulus microfilarial densities 15,80 and 180 days after a first dose of ivermectin. Acta Trop 2011; 120 Suppl 1: S91-99

17. Babu S, Bhat SQ, Kumar NP, Jayantasri S, Rukmani S, Kumaran P, Gopi PG, Kolappan C, Kumaraswani V, Nutman TB. Human type 1 and 17 response in latent tuberculosis are modulated by coincident filarial infection through cytotoxic T-lymphocyte antigen-4 and programmed death-1. J Infect Dis 2009; 200: 288-298

18. Krushna NSA, Shiny C, Verma P, Nithya D, Basker P, Elango S, Babu S, Narayanan RB. Wuchereria bancrofti: diminished platelet activation in filarial patients. Exp Parasitol 2010; 125: 114-123

19. Brattig NW. Pathogenesis and host response in human onchocercosis: impact of Onchocerca filariae and Wolbachia endobacteria. Microbes Infect 2004; 6: 113-128

20. Udall DN. Recent updates on onchocerciasis: diagnosis and treatment. Clin Infect Dis 2007; 44: 53-60

21. Sbeity ZH, Jaksche A, Martin S, Loeffler KU. Loa loa microfilariasis in the eyelid: case report of the first periocular subcutaneous manifestation in Germany. Graefe's Arch Clin Exp Ophthalmol 2006; 244: 883-884

22. Ngwira BM, Jabu $\mathrm{CH}$, Kanyongoloka $\mathrm{H}$, Mponda M, Crampin AC, Branson K, Alexander ND, Fine PE. Lymphatic filariasis in the Karonga district of northern Malawi: a prevalence survey. Ann Trop Med Parasitol 2002; 96: 137-144

23. Igbal J, Sher A. Determination of the prevalence of lymphatic filariasis among migrant workers in Kuwait by detecting circulating filarial antigen. J Med Microbiol 2006; 55: 401-405

24. Dreyer G, Addiss D, Williamson J, Noroes J. Efficacy of co-administered diethylcarbamazine and albendazole against Wuchereria bancrofti. Trans R Soc Trop Med Hyg 2006; 100: 1118-1125

25. Ramaiah KD, Das PK, Vanamail P, Pani SP. Impact of 10 years of diethylcarbamazine and ivermectin mass administration on infection and transmission of lymphatic filariasis. Trans R Soc Trop Med Hyg 2007; 101: 555-563

26. Tisch DJ, Michael E, Kazura JW. Mass chemotherapy options to control lymphatic filariasis: a systematic review. Lancet Infect Dis 2005; 5: 514523

27. Sumadhya DF, Chaturaka R, Senaka R. Current evidence on the use of antifilarial agents in the management of bancroftian filariasis. J Trop Med 2011; article ID 175941, doi: 10.1155/2011/175941

28. Opara KN, Fagbemi BO. Population dynamics of onchocerca volvulus microfilariae in human host after six years of drug control. J Vector Borne Dis 2008; 45: 29-37

29. Katabarwa M, Eyamba A, Habomugisha P, Lakwo T, Ekobo S, Kamgno J, Kuete T, Ndyomugyenyi R, Onapa A, Salifou M, Ntep M, Richards FO. After a decade of annual dose mass ivermectin treatment in Cameroon and Uganda, onchercosis transmission continues. Trop Med Int Health 2008; 13: 1196-2003
30. Mas J, Ascaso C, Escaramis G, Abellana R, Duran E, Sima A, Sánchez MJ, Nkogo PR, Nguema $R$, Untoria MD, Echeverra MA, Ardevol MM, Jiménez Anta MT. Reduction in the prevalence and intensity of infection in Onchocerca volvulus microfilariae according to ethnicity and community after 8 years of ivermectin treatment on the island of Bioko, Equatorial Guinea. Trop Med Int Health 2006; 11: 1082-1091

31. Osei-Atweneboana MY, Eng JKL, Bookye DA Gyapong JO, Prichard RK. Prevalence and intensity of Onchocerca volvulus infection and efficacy of ivermectin in endemic communities in Ghana: a two-phase epidemiological study. Lancet 2007; 369: 2021-2029

32. Bal MS, Mandal NN, Das MK, Kar SK, Sarangi SS, Beuria MK. Transplacental transfer of filarial antigens from Wuchereria bancrofti-infected mothers to their offspring. Parasitology 2010; 137: 669-673

33. Dietrich M, Kern P. Tropenlabor - Diagnostik für die ärztliche Praxis mit einfacher Laborausrüstung. Gustav Fischer Verlag Stuttgart, 1983, pp 31-34, p 124

34. El Bassiouny AE, el Gammal NE, Mahmoud AM. Isolation and concentration of microfilariae from peripheral blood of Wuchereria bancrofti infected patients by density gradient centrifugation. J Egypt Soc Parasitol 1993; 23: 255-261

35. Weil GJ, Steel C, Liftis F, Li BW, Mearns G, Lobos E, Nutman TB. A rapid-format antibody card test for diagnosis of onchocerciasis. J Infect Dis 2000; 182: 1796-1799

36. Burbelo PD, Leahy HP, ladarola MJ, Nutman TB. A four-antigen mixture for rapid assessment of Onchocerca volvulus infection. PLoS Negl Trop Dis 2009; 3 (5) e438

37. Burbelo PD, Ramanathan $R$, Klion $A D$, ladarola MJ, Nutman TB. Rapid, novel, specific, highthroughput assay for diagnosis of Loa loa infection. J Clin Microbiol 2008; 46: 2298-2304

38. Ramah N, Shenoy RK, Nutman TB, Weiss N, Gilmour K, Maizels RM, Yazdanbaksh M, Sartono E. Multicentre laboratory evaluation of Brugia rapid dipstick test for detection of brugian filariasis. Trop Med Int Health 2003; 8: 895-900

39. Wattal S, Dhariwal AC, Ralhan PK, Tripathi VC, Regu K, Kamal S, Lai S. Evaluation of Og4C3 antigen ELISA as a tool for detection of bancroftian filariasis under lymphatic filariasis elimination programme. J Commun Dis 2007; 39: 75-84

40. Bal MS, Beuria MK, Mandal NN, Das MK. Antigenemia in young children living in Wuchereria bancrofti-endemic areas of Orissa, India. Trans R Soc Trop Med Hyg 2009; 103: 262-265

41. Rocha A, Braga C, Belém M, Carrera A, AguiarSantos A, Oliviera P, Texeira MJ, Furtado A. Comparison of tests for the detection of circulating filarial antigen (Og4C3 ELISA and AD12-ICT) and ultrasound in diagnosis of lymphatic filariasis in individuals with microfilariae. Mem Inst Oswaldo Cruz 2009; 104: 621-625

42. Zhong M, McCarthy JS, Bierwert L, Lizotte-Warniewski M, Chanteau S, Nutman TB, Ottesen EA, Williams SA. A polymerase chain reaction assay for detection of the parasite Wuchereria bancrofti in human blood samples. Am J Trop Med Hyg 1996; 54: 357-363

43. McCarthy JS, Zhong M, Gopinath R, Ottesen EA, Williams SA, Nutman TB. J Infect Dis 1996; 173: 1510-1514
44. Rao RU, Weil GJ, Fischer K, Supali T, Fischer P. Detection of Brugia parasite DNA in human blood by real time PCR. J Clin Microbiol 2006; 44: 38873893

45. Mishra K, Raj DK, Hazra RK, Dash AP, Supakar PC. The development and evaluation of a single step multiplex PCR method for simultaneous detection of Brugia malayi and Wuchereria bancrofti. Mol Cell Probes 2007; 21: 355-362

46. Tang TH, López-Vélez R, Lanza M, Shelley AJ, Rubio JM, Luz SL. Nested PCR to detect and distinguish the sympatric filarial species Onchocerca volvulus, Mansonella ozzardi and Mansonella perstans in the Amazon region. Mem Inst Oswaldo Cruz 2010; 105: 823-828

47. Rao RU, Bockarie MJ, Susapu M, Laney SJ, Weil GJ. A qPCR-based multiplex assay for the detection of Wuchereria bancrofti, Plasmodium falciparum and Plasmodium vivax DNA. Trans $\mathrm{R} S \mathrm{Soc}$ Trop Med Hyg 2009; 103: 365-370

48. Aonuma $\mathrm{H}$, Yoshimura A, Kobayashi T, Okado K, Badolo A, Nelson B, Kanuka H, Fukumoto S. A single fluorescence-based LAMP reaction for identifying multiple parasites in mosquitoes. Exp Parasitol 2010; 125: 179-183

49. Supali T, Ismid IS, Wibowo H, Djuardi Y, Majawati E, Ginanjar P, Fischer P. Estimation of the prevalence of lymphatic filariasis by a pool screen PCR assay using blood spots collected on filter paper. Trans R Soc Trop Med Hyg 2006; 100: 753-759

50. Fink DL, Fahle GA, Fischer S, Fedorko DF, Nutman TB. Toward molecular parasitologic diagnosis: enhanced diagnostic sensitivity for filarial infections in mobile populations. J Clin Microbiol 2011; 49: 42-47

51. Zamarron Fuertes $P$, Perez-Ayala A, Perez-Molina JA, Norman FF, Monge-Maillo B, Navarro M, Lopez-Vélez R. Clinical and epidemiological characteristics of imported infectious diseases in Spanish travellers. J Travel Med 2010; 17: 303-309

52. Weller PF, Simon HB, Parhurst BH, Medrek TF. Tourism-acquired Mansonella ozzardi microfilaremia in a regular blood donor. J Am Med Ass 1978; 240: 858-859

53. Lipner EM, Law MA, Barnett E, Keystone JS, von Sonnenburg F, Loutan L, Prevots DR, Kilon AD, Nutman TB. Filariasis in travelers presenting to the GeoSentinel Surveillance Network. PLoS Negl Trop Dis 2007; Dec 26; 1(3): e88

54. AuBuchon JP, Dzik WH. Survival of Loa loa in banked blood. Lancet 1983; 321: 647-648

55. Gönnert R. Zur Lebensdauer menschlicher Mikrofilarien. Zentrbl Bakt Parasit Infek Orig 1943; 149: $75-81$

56. Knott J. The periodicity of the microfilaria of Wuchereria bancrofti. Preliminary report of some injection experiments. Trans R Soc Trop Med Hyg 1935; 29: 59-64

57. Hawking $F$. The transference of microfilaria bancrofti into natural and unnatural hosts. Ann Trop Med Parasit 1940: 34: 121-129

58. Rao R, Weil GJ. In vitro effects of antibiotics on Brugia malayi worm survival and reproduction. J Parasitol 2002; 88: 605-611

59. Coulibaly YI, Dembele B, Diallo AA, Lipner EM, Doumbia SS, Coulibaly SY, Konate S, Diallo DA, Yalcouye D, Kubofcik J, Doumbo OK, Traore AK, Keita AD, Fay MD, Traore SF, Nutman TB, Kion AD. A randomized trial of doxycyline for Mansonella perstans infection. N Engl J Med 2009; 361: 1448-1458 
60. Haarbrink M, Abadi GK, Buurman WA, Dentener MA, Terhell AJ, Yazdanbakhsh M. Strong association of interleukin- 6 and lipopolysaccharide-binding protein with severity of adverse reactions after diethylcarbazamine treatment of microfilaremic patients. J Infect Dis 2000; 182: 564-569

61. Cotreau MM, Warren S, Ryan JL, Fleckenstein L, Vanapalli SR, Brown KR, Rock D, Chen CY, Schwertschlag US. The antiparasitic moxidectin safety, tolerability, and pharmocokinetics in humans. J Clin Pharm 2003; 43: 1108-1115

62. Maxwell CA, Curtis CT, Haji H, Kisumku S, Thalib Al, Yahya SA. Control of bancroftian filariasis by integrating therapy with vector control using polystyrene beads in wet pit latrines. Trans R Soc Trop Med Hyg 1990; 84: 709-714

63. Drobniewski FA. The safety of bacillus species as insect vector control agents. J Appl Bacteriol 1994; 76: 101-109

64. Li BW, Chandrashekar R, Well GJ. Vaccination with recombinant filarial paramyosin induces partial immunity to Brugia malayi infections in jirds. J Immunol 1993; 50: 1881-1885

65. Taylor MJ, Jenkins RE, Bianco AE. Protective immunity induced by vaccination with Onchocerca volvulus tropomyosin in rodents. Parasite Immunol 1996; 18: 219-225

66. Jenkins RE, Taylor MJ, Gilvary NJ, Bianco AE. Tropomyosin implicated in host protective responses to microfilariae in onchocerciasis. Proc Natl Acad Sci USA 1998; 95: 7550-7555

67. Ungeheur M, Elissa N, Morelli A, Georges AJ, DeIoron P, Debre P, Bain O, Millet P. Cellular responses to Loa loa experimental infection in mandrills (Mandrillus sphinx) vaccinated with irradiated infective larvae. Parasite Immunol 2000 ; 22: 173-183

68. Akue JP, Morelli A, Moukagni R, Moukana H, Blampain AG. Parasitological and immunological effects induced by immunization of Mandrillus sphinx against the human filarial Loa loa using infective stage larvae irradiated at $40 \mathrm{Krad}$. Parasite 2003; 10: 263-268

69. Vedi S, Dangi A, Hajela K, Misra- Bhattacharya S. Vaccination with $73 \mathrm{kDa}$ recombinant heavy chain myosin generates high level of protection against Brugia malayi challenge in jird and mastomys model. Vaccine 2008; 26: 5997-6005

70. Bird GWG, Menon KK. Survival of microfilaria bancrofti in stored blood. Lancet 1961; 278: 721

71. Kremer M. Note sur la survie des microfilaires en sang conservé. Rev Fr Transfus 1969; 12: 281-282

72. Bregani ER, Balzarini L, Ghiringhelli, Tarsia P. Transfusional Mansonella perstans microfilariasis. Parasitologia 2003; 45: 71-72

73. Bregani ER. Filariasis due to blood transfusion. Blood Transfus 2010; 8: 129

74. Nutman TB. Experimental infections of humans with filariae. Rev Infect Dis 1991; 13: 1018-1022

75. Choudhury N, Murthy PK, Chatterjee RK, Khan MA, Ayyagari A. Transmission of filarial infection through blood transfusion. Indian J Pathol Microbiol 2003; 46: 367-370

76. Janssens PG, van Bogaert T, Tverdy G, Wanson $M$. Réfexion sur le sort des microfilaires de Loa loa dans l'organisme humain parasité. Manifestations viscérales provoquées par leur infiltration dans les tissus. Bull Société Pathol Exotique 1958; 51: 632-645

77. Akinboye DO, Ogunrinade AF. Malaria and loiasis among blood donors at Ibadan, Nigeria. Trans R Soc Trop Med Hyg 1987; 81: 398-399
78. Chikwem JO, Mohammed I, Okara GC, Ukwandu NC, Ola TO. Prevalence of transmissible blood infections among blood donors at the University of Maiducuri Teaching Hospital, Maiguguri. East Afr Med J 1997; 74: 213-216

79. Salawu L, Murainah HA. Pre-donation screening of intending blood donors for antibodies to infectious agents in a Nigerian tertiary health institution: a pilot study. Afr J Med Sci 2006; 35 : 453-456

80. Wiwanitkit V. Filariasis due to blood transfusion: a topic in tropical medicine. Blood Transfus 2009; 7: 151

81. Cupp MS. Perspectives on the in vitro culture of filariae. In Vitro Cell Dev Biol 1991; 27A: 505-508

82. Khunkitti W, Fujimaki Y, Aoki Y. In vitro antifilarial activity of extracts of the medicinal plant Cardiospermum halicacabum against Brugia pahangi. J Heminthol 2000; 74: 241-246

83. Wang SH, Zheng HJ. Survival and infectivity of Brugia malayi microfilariae after cryopreservation. Southeast Asian J Trop Med Public Health 1991; 22: 165-167

84. Rao RU, Atkinson LJ, Vanderwall RP, Weil GJ. Brugia malayi: effects of gamma irradiation on adult worms and their intracellular Wolbachia species. Exp Parasitol 2005; 109: 87-93

85. Pexioto CA, Rocha A, Aguiar-Santos A, Florencio MS. The effects of diethylcarbamazine on the ultrastructure of microfilariae of Wuchereria bancrofti in vivo and in vitro. Parasitol Res 2004; 92: 513-517

86. Walter RD, Wittich RM, Kuhlow F. Flaricidal effect of mefloquine on adults and microfilariae of Brugia patei and Brugia malayi. Trop Med Parasitol 1987; 38: 55-56

87. Leroy E, Baize S, Wahl G, Egwang TG, Georges AJ. Experimental infection of a non-human primate with Loa loa induces transient strong immune activation followed by peripheral unresponsiveness of helper T cells. Infect Immun 1997; 65: 1876-1882 